\title{
A Representação Dilacerada em Georges Bataille e Francis Bacon
}

\author{
Wanda de Paula Tofani
}

Resumo

\begin{abstract}
A partir das relações entre mímesis e representação, investigo, comparativamente, as obras de Georges Bataille e de Francis Bacon. Ambos produziram obras radicais, segundo o eixo conceitual de desconstrução da semelhança antropomórfica ideal. Abordando suas obras pela noção de sintoma e da figuralidade freudiana, repenso a reversão da representação em apresentação e, principalmente, sua coalescência.
\end{abstract}

Palavras-chave: Representação. Mímesis. Figuralidade. Georges Bataille. Francis Bacon.

O entrelaçamento das artes literárias e visuais constitui o terreno de eleição para meu percurso investigativo, fundamentado pelos conceitos de representação e mímesis, assim como pela busca de seus desdobramentos ou rastros nas artes do século XX, após suas mortes anunciadas. Busco estabelecer, resumidamente, o entendimento desses conceitos em suas relações com as noções de imagem e figura e sua posterior refutação, desencadeada por movimentos artísticos que anunciam as premissas do modernismo.

A noção clássica de representar define-se como o processo de apresentar de novo algo que está presente alhures, estando, portanto, em seu lugar. No lugar da representação há, pois, um ausente no tempo e no espaço, operando-se uma substituição. Esse ausente, pela representação, torna-se o mesmo, mas não é cópia, nem presença e, sim, efeito de presença. Representar é assim mostrar, exibir, apresentar uma presença, através de uma operação mimética e ao mesmo tempo constitui uma espetacularidade, uma auto-apresentação, que constrói a identidade daquilo que é representado. Como todo signo, a representação tem dupla dimensão e duplo efeito: reflexiva, apresentar-se e transitiva, representar algo, seu efeito sendo, simultaneamente, o de sujeito e de objeto (MARIN, 1981, p. 9-10).

Tal substituição traduz uma visão do mundo condicionada pela mímesis, dandose, pois, num espaço de semelhanças, onde as coisas se tornam visíveis, refletindo-se e duplicando-se pelas palavras. Mímesis e representação, intimamente entrelaçadas, fizeram, pois, das artes, o espelho do mundo, tanto na descrição quanto na pintura. A mímesis, porém, que em sua origem compreendia a semelhança e a diferença, embora a última se subordinasse à primeira, foi degradada para a noção de imitatio. 
A semelhança entre a coisa ou o ser ausente e sua imagem presente na representação verbal ou icônica era, aliás, fator imprescindível para uma representação bem sucedida. A estrutura do signo-representação caracterizava-se pela duplicidade do repetir e do intensificar e seu efeito era a constituição de um sujeito, por reflexão do dispositivo representativo. Sujeito solar, cuja razão o tornava capaz de modelar e produzir suas representações. O cogito cartesiano fundara o mundo a partir do sujeito que pensa, racionalmente, e que era capaz de construir um mundo, através das idéias claras e distintas, retirando-lhe, contudo, as irregularidades advindas dos afetos. (COSTA LIMA, 2000, p. 87-93). Consolidava-se, assim, no século XVII, o processo epistemológico e filosófico do observador renascentista - sujeito albertiniano - que, de um único ponto de vista, contemplava o mundo através de uma janela, traduzida pela moldura do livro ou da tela.

As pinturas desse período acoplam as premissas narrativas da representação, sendo passíveis de legibilidade, além de sua óbvia visibilidade. Nesse contexto imbricam-se o legível e o visível numa tessitura constituída pelos discursos e pelos percursos do olhar. Tem-se, então, na pintura, dois fatores determinantes para o acesso ao conhecimento.

Duas obras-primas - Las Meninas de Velásquez e Dom Quixote de Cervantes congregam a intensificação do modelo representativo, uma vez que apresentam o processo de representação. Ao exibirem sua própria construção e desvelarem o ciclo da representação, dobram-se sobre si mesmas, constituindo a meta-representação. Contudo, ao fazê-lo, desconstroem a representação e apontam para sua colocação em crise (MARIN, 1997, p. 40). Crise essa que se consolidaria cerca de dois séculos mais tarde, quando a noção de representação unitária, modelada racionalmente por um sujeito central, tornar-se-á insustentável, para um "sujeito múltiplo, portador de um olhar plural, um não-sujeito", em suma (MARIN, 1994, p. 250).

Os movimentos artísticos do século XIX, dirigidos pelo primado da função estética, que concebe as artes como tendo um fim em si mesmas, enquanto reserva ao receptor um papel proeminente, vão definitivamente abalar a representação clássica. Abre-se, pois, aos poetas e aos artistas, um campo ilimitado de possibilidades, cujo eixo preponderante será afirmado pela poética da negatividade, que se consolidará no século $X X$.

A mímesis e a representação, doravante refutadas, serão, no entanto, ao final desse século, objeto de reconsideração por alguns teóricos das artes, dentre os quais destaco Luiz Costa Lima e Georges Didi-Huberman. O primeiro propõe o sentido de uma mímesis desvinculada da imitação e independente da realidade, mas passível de propor uma nova visão da realidade. A representação, por sua vez, não sendo mais a "equivalência subjetiva de uma cena externa e objetiva", se desdobra como "representação-efeito, provocada não por uma cena referencial, mas pela expressão da cena em alguém". Refutando a concepção moderna de sujeito solar, como aquele que é origem e comando das próprias representações, este autor ressalta a concepção de "sujeito fraturado", cuja posição não está definida a priori, dependendo de variáveis contextuais (COSTA LIMA, 2000, p. 21-27). Trata-se, aliás, na acepção de DidiHuberman, de um "sujeito dilacerado".

Buscando tecer as relações fundadoras entre imagem, figura, mímesis e representação, ressalto a gênese das imagens a partir de seu vínculo com a busca de entendimento do mundo e da morte. Assim, a primitiva produção de imagens resgata o sentido físico do estatuto experimental e o sentido gnoseológico de uma apreensão do mundo. Da mesma forma, vinculando-se à morte, a imagem torna-se, pelo simulacro, 
um modo de perpetuar a lembrança dos mortos. Tal simulacro, pautando-se pela semelhança, inaugura a imagem.

O termo figura, por sua vez, contempla as noções de "forma plástica", de aparência externa, de contorno e de ficção, ressaltando-se, na imagem e no discurso, seu registro de "alusão velada em suas diversas formas". Daí que, o entendimento do conceito de figura será matizado pela noção de forma gramatical, retórica e lógica, impregnando-se ainda do sentido de desvio, desde que se trata de uma forma de discurso que se desvia de seu uso normal e mais óbvio. Com o advento do Cristianismo confere-se à figura um outro significado, ao deslocá-la para além de sua aparência visível, inserindo-a num contexto profético e teleológico, como configuração de algo a se realizar no futuro, o qual, aliás, se identifica ao Juízo Final. A figura é, então, algo real e histórico, que aponta para o futuro e demanda uma interpretação (AUERBACH, 1997, p. 13-16 e p. 25).

Para Didi-Huberman, a acepção de figura, como uma configuração do mundo visível, depara-se com o paradoxo de figurar o que não é figurável, ou seja, o mistério da Encarnação e a visibilidade do Verbo divino. Figurar seria, então, transpor o sentido numa outra figura, dar-lhe um outro aspecto, mudar sua visibilidade, incluindo nela a alteridade. Figurar se aproximaria, assim, do sentido de desfigurar ou prefigurar. A figura resultaria de um procedimento que abarcaria a semelhança, a recriação e até mesmo a criação, conjugando a noção de estar no lugar de, portanto, de representar e, principalmente, a noção de presença, de estar aí, diante de nós. Importa ressaltar, que se a figura cristã visava, além de seu valor de representação, um autêntico valor de presença, ela o era tanto mais pelo modo de aparição, do que pela própria aparência, decorrendo daí sua eficácia litúrgica (DIDI-HUBERMAN, 1995a, p. 231-234).

Enfatizo as questões relativas à gênese das figuras cristãs por entender que tal constituição se perde, no Renascimento, ao se privilegiar as aparências visíveis e ao se consolidar a teoria da representação, enquanto seus procedimentos constitutivos parecem ser recuperados, no modernismo, embora desligados da questão religiosa. Assim, a Figura - aqui escrita com letra inicial maiúscula - será entendida como desvio e deslocamento, comportando o dilaceramento da semelhança ideal, no sentido de uma origem figural conformada à imagem divina. Trata-se de uma Figura que não se refere mais, explicitamente, ao resultado de um processo figurativo, como usualmente se entende a figuração. Figura, em suma, que contempla a ausência de uma significação unívoca e que, como tal, privilegia a indeterminação e a disseminação de sentidos.

Esta acepção figural pode ser detectada no pensamento de Georges Bataille, tanto nos textos quanto nas imagens que ele seleciona para a revista de arte Documents, da qual foi editor em 1929 e 1930. Inserido num contexto artístico que já convivia com rupturas diversas, desde Mallarmé e Manet, ele radicalizará estas posturas transgressivas por um acerbo pensamento filosófico-crítico, em sua obra em geral.

Nessa revista, Bataille privilegiará o trabalho das palavras e das imagens como um nietzscheano "gaio saber visual", abarcando temas doutrinários, arqueológicos, artísticos e etnográficos, enquanto os friccionava de modo inédito e apresentava obras contemporâneas e obras rejeitadas pela historiografia tradicional. Esta conjunção heteróclita advinha da experiência surrealista; Bataille, construindo uma estética paradoxal, que invertia as clássicas noções de gosto, beleza e forma e ressaltava, respectivamente, as noções de desejo, intensidade e informe (DIDI-HUBERMAN, 
1995b, p. 12-18). A noção de informe era, aliás, um rico operador teórico que abalaria e dilaceraria a idealidade da construção filosófico-formal da figura humana.

As questões desenvolvidas por Bataille, em seus escritos e na manipulação prática das imagens convocadas para dialogar com os textos da revista, permitem-me enfocar questões intrínsecas à pintura de Francis Bacon; pintura que parece estar prefigurada em textos e imagens de Documents. Trata-se de uma pintura anticonvencional que se pautou pela violência e exacerbada carga emocional, buscando apresentar a "brutalidade dos fatos", impressos na experiência vivida, e criando imagens que fossem fiéis a seu sistema nervoso, como ele próprio afirmava. Expressando a transitoriedade da experiência humana, Bacon, assim como Bataille, tinha como eixo de sua obra pictural a conjunção ocasional entre arte e vida, enquanto elaborava um diálogo entre figuração e abstração, conjugando aspectos naturalistas e sua simultânea e parcial obliteração. Buscava registrar essa brutalidade, capturando as aparências transitórias de fragmentos da realidade. Seu intuito era conjurar o caráter narrativo e ilustrativo das pinturas do passado, fazendo-o a partir do isolamento da Figura, enquanto nos trípticos, a negação de uma continuidade temporal e espacial, pelo procedimento da repetição, evitava que uma história se instalasse. A Figura humana distorcida e atormentada, em estado de profunda tensão, inserida em espaços rasos e claustrofóbicos, era seu tema predominante, sendo traduzida pela violência de sua conformação dilacerada e pela exacerbação da gestualidade pictórica.

Apelando intensamente aos sentidos, sua pintura parece captar forças invisíveis, que podem ser percebidas pelas tensões que se digladiam na tela, seja por suas figuras fragmentadas e convulsionadas, seja pelo uso exacerbado de pinceladas e esfregaços justapostos, que fazem pulsar os corpos e as coisas na tela inscritos, constituindo, aliás, uma zona de indiscernibilidade (DELEUZE, 1996, p. 40-41). A exacerbação das distorções e dos procedimentos pictóricos permite-me pensar quão adequada às pinturas de Bacon parece ser a assertiva de André Breton, em Nadja: "A beleza será convulsiva ou não será".

Enfocando os processos formais advindos de uma postura receptiva ao acaso, sua pintura contém premissas surrealistas, embora constitua uma linguagem sui generis, no âmbito de estéticas experimentais já consolidadas, por via de uma tradição de rupturas. Colocando-se à espreita do fato poético, conduzido pelo automatismo psíquico e desenvolvido pela incongruência das relações entre os termos, os fatos e os elementos dos textos e das imagens, Bacon e Bataille adotam, de certa forma, práticas surrealistas, apesar de Bacon não se inserir neste movimento e de Bataille ter sido um opositor do surrealismo de Breton. Bataille, aliás, propugnava as experiências conformadas pela realidade, em oposição às conformadas pelo onírico.

Determinados aspectos das obras de Bataille e Bacon apontam as homologias de seus processos operatórios, conduzidos pela transgressão dos princípios gerais da noção de semelhança antropomórfica ideal. A noção batailleana de informe, seja na letra, seja na imagem, colocava em jogo essa semelhança, pela reivindicação de semelhanças transgressivas ou dessemelhanças. Semelhanças, em suma, "cruéis, dilacerantes e dilaceradas", que propiciavam uma "heurística do desastre", onde o corpo tornava-se um organismo consagrado à desfiguração, ao suplício e à animalidade (DIDI-HUBERMAN, 1995b, p. 5-10). Esse dilaceramento da semelhança ideal induz ao entendimento da imagem dentro de um duplo regime, conjugando fixidez e mobilidade, como uma insubordinação das relações da imagem e de seus modelos, e frustrando a reprodução do semelhante. Constrói-se assim um autêntico trabalho sobre as formas verbais e visuais, doravante transgredidas e transgressoras. 
(DIDI-HUBERMAN, 1995b, p. 10-12) Esse duplo regime traduz-se claramente na pintura de Bacon, cuja instabilidade conjuga a dualidade de formas naturalistas e de formas abstratas; de grandes chapados de cor, justapostos ao frêmito colorido dos corpos.

Considerando tanto as conexões quanto as singularidades de suas obras, destaco as relações da pintura de Bacon com a noção batailleana de informe; noção que ressalta, sobretudo, as relações processuais, estruturais e dinâmicas entre as formas, passíveis de fazer deslocar o pensamento por suas montagens figurativas. Montagens que são, aliás, a principal ferramenta das desmontagens teóricas de Bataille, confrontando a noção do informe, entendida como deformação ou dilaceramento da semelhança, com as tradicionais noções de forma e de antropomorfismo.

Destaco a presença do erotismo, na obra de ambos. Para Bataille, o erotismo era uma das práticas de excesso, estreitamente vinculado ao sagrado, sendo sua origem e seu domínio o da violência e da transgressão, em oposição ao domínio do trabalho e da produção. Bataille desenvolveu seu pensamento sobre o erotismo de forma programática, estudando-o do ponto de vista da história, das religiões e das convenções sociais, explicitando seus interditos e suas superações (BATAILLE, 2004). Quanto a Bacon, a violência formal e pictórica constituiu expressiva parte do conjunto de suas pinturas, embora ele próprio considerasse não haver violência em suas imagens. Além disso, Bacon impregnava suas pinturas de uma atmosfera erótica, seja por sugerir ou apresentar atos sexuais, seja por suscitar uma histerização, uma erotização do olhar, através de um paroxismo dionisíaco dos corpos re-presentados.

Enfocando duas das touradas de Bacon (Figuras), minha leitura sugere a ligação destas pinturas com o evento da tourada, na História do olho de Bataille, cujos personagens adolescentes exacerbam seus jogos sexuais, dialogando com a transgressão e a morte. Minhas sensações diante das brancas projeções de tinta levam-me a considerar a semelhança entre essas projeções e as formas arredondadas e brancas desta novela - olhos, ovos, testículos de touro. Semelhança, contudo, indeterminada, uma vez que constituem um acidental recurso pictórico. Buscando entender o efeito pungente e inquietante dessas projeções, reporto-me à noção didihubermaniana de pan, com o sentido e o efeito "de pânico, de vertigens e de quedas", diante dessas imagens que me perturbam. Paralelamente, a fugacidade dessa sensação poderia se identificar à noção de éclat, como a vivência de uma fulguração (DIDI-HUBERMAN, 1985, p. 10-11 e p. 69). Ambos são efeitos instantâneos e paradoxais que fazem punção, como uma "precipitação disjuntiva" e um "desastre na ordem do visível". (DIDI-HUBERMAN, 1985, p. 44 e p. 93). Tais formas, num contínuo revezamento, estabilizam-se como procedimentos pictóricos, transformando-se, porém, instantaneamente, nos brancos glóbulos da obsessão de Bataille, que faço minha e, assim, infindavelmente.

http://www.alexalienart.com/alexgallery2.htm Study for Bullfight No.1, 1969.

Óleo sobre tela, $198 \times 147,5 \mathrm{~cm}$. Acesso em 22 nov. 2006. http://www.alexalienart.com/alexgallery2.htm Second Version of "Study for Bullfight No.1",1969.

Óleo sobre tela, $198 \times 147,5 \mathrm{~cm}$. Acesso em 22 nov. 2006.

O questionamento do conceito de representação e de suas relações com a mímesis se constrói a partir da análise crítica dos processos constitutivos das poéticas de Bataille e de Bacon, sob as premissas da figuralidade freudiana e da noção de 
sintoma. Daí que, havendo desconstrução dos modelos que nortearam as artes do passado, nas obras de Bataille e de Bacon, como, aliás, em muitas outras, é significativa a reversão do conceito de representação, no sentido da emergência de seu componente reflexivo e obliterado: a apresentação. As artes modernas, privilegiando a autonomia das linguagens, destacam seus processos estruturais, em detrimento de seus temas. Desvelando seus fazeres e exaltando-os, enquanto problematizam, pela indeterminação e instabilidade formal, a questão do significado, as artes resgatam a noção de apresentação, refutando o conceito clássico de representação, uma vez que se torna inexeqüível a unanimidade e a estabilidade da interpretação, num mundo oscilante e em face de um sujeito, ele próprio dilacerado.

A reabilitação do conceito de mímesis propugna seu entendimento, como um processo que implica a equivalência, tanto quanto a diferença. Não mais sendo imitação, a mímesis reabilitada produziria uma "semelhança dessemelhante", no sentido de uma semelhança que incluísse a diferença e onde, o referente seria fragmentado, guardando, contudo, rastros ou sintomas de um processo figural identificado à figuralidade freudiana. Processo esse que, conformado de modo similar às associações e montagens figurativas incongruentes dos sonhos, constitui Figuras indeterminadas e espaços oscilantes, cuja pregnância os abrem à multiplicidade de sentidos. Tem-se, pois, a partir do trabalho de condensação e de deslocamento das imagens do sonho, a impossibilidade de uma síntese formal, uma vez que o sonho é governado por uma lei de labilidade. A figuralidade, não contemplando a representação de relações lógicas, está, portanto, incapacitada de significar, univocamente, de tornar visíveis e legíveis as relações entre as figuras.

No que concerne à semelhança, o trabalho do sonho não contempla a idéia da mímesis como imitação. Ao se postular o processo da mímesis, como uma figuração em ato, que faz com que duas coisas anteriormente separadas se toquem, tem-se uma noção de semelhança que não contempla o mesmo, mas que se infecta de alteridade, conformando, aliás, novos elos de semelhança. Há, portanto, na figuralidade, um dilaceramento da semelhança da ordem do natural.

Importa, ainda, destacar a mutação do eixo vertical do visível para o eixo horizontal do carnal, nas obras de ambos. Mutação conceitual e espacial que traduz o movimento da idealidade à animalidade, colocando-nos frente à alteridade $e$ provocando a vertigem de um espaço abissal. Vertigem que se concretiza visualmente na pintura de Bacon, onde os corpos são governados pelo eixo do "baixo materialismo" batailleano. A obra de Bataille relaciona-se com a teoria freudiana, uma vez que, para ele, o materialismo autêntico não existia sem uma teoria das formas duplicada por uma teoria do psíquico. A referência psicanalítica em seu pensamento crítico situava-se no nível dos princípios e processos de deformação das imagens. O inconsciente freudiano e a noção de sintoma, não sendo fixos, possibilitavam, em suma, abalar e decompor, prática e teoricamente, todas as certezas ilusórias de nossa face humana.

Considerando o elo da crítica de arte francesa com a psicanálise, Didi-Huberman ressalta a noção de sintoma psicanalítico, transpondo-o para o entendimento de sintoma verbal e visual, apreensível nas imagens, e que, por ser instável e equívoco, desagrega a unidade discursiva, faz intrusão e impõe o impensável. Devido a suas estruturas abertas, ao jogo figural, aos detalhes, às imagens fantasmáticas, o sintoma, como um trabalho em termos brutos e materiais do significante, libera o conteúdo da imagem, dispersando-o de modo prismático. Com a noção de sintoma, a dedução progressiva de um símbolo e as certezas decorrentes dessa dedução não são mais possíveis, devido ao interminável deslocamento simbólico. O modelo sintomal 
conduzido pelo desejo contempla a irrupção do recalque, daquilo que guardado no recôndito do inconsciente se forma ao se deformar, furtando-se à razão e abrindo o saber (DIDI-HUBERMAN, 1990, p. 176-180), ou, como desejava Bataille, permitindo o acesso ao não-saber.

A pintura de Bacon configurada pelo drama e pelo desejo estaria atravessada pela energia e intensidade dos sintomas da transitoriedade e do tormento dos corpos; sintomas ainda de uma tensão que neles circula e neles se concentra, deixando-os no limite da própria destruição, no frágil limite entre vida e morte. O trabalho da figuralidade dilacera a semelhança, abrindo a figura em todos os sentidos. Tal dilaceramento "cava" a representação, chama a Figura e sua apresentação, doravante fundada no desvio, sua essência. Trabalho, enfim, que frustra a legibilidade e visibilidade de uma representação clássica (DIDI-HUBERMAN, 1990, p. 182-186).

Grosso modo, nas artes modernas, tem-se que a emergência da apresentação não refuta inapelavelmente a permanência de alguns aspectos da representação, sobretudo no que se refere aos traços de determinada realidade, que dialogam com a construção poética. Na experiência estética, ao se realizar a produção verbal ou visual de algo antes inexistente ou invisível, trabalha-se com vestígios, rastros ou sintomas de uma realidade feita de lacunas, enquanto explora seus silêncios e vazios. Trata-se de uma representação sintomal (DIDI-HUBERMAN, 1990), impossibilitada de construir uma apreensão totalizante e, portanto, una e estável, tendo em vista sua desconexão de um referente previamente dado.

Paralelamente à noção de representação-efeito resgatada e desenvolvida por Costa Lima e à de representação sintomal enfocada por Didi-Huberman, avanço, especulativamente, a noção de representação dilacerada, na qual, a preponderância da apresentação não impede a emergência de vestígios, rastros ou reflexos figurais, potencialmente referenciados, mas autônomos e nem sempre identificáveis. Tais referentes, sendo lábeis, inscrevem-se prismática e instavelmente, conjugando uma dispersão de sentidos, eles próprios dilacerados, num caleidoscópio de possibilidades e impossibilidades. A representação dilacerada se concretizaria, momentaneamente, pelo jogo da facticidade sintomal e pelo jogo da literalidade ou da plasticidade. Jogos conduzidos e experienciados pelo produtor e pelo receptor, ambos aptos a conceber sentidos, a priori indeterminados, através de formas de legibilidade ou de visualidade, condicionadas, por sua vez, às determinações singulares de sujeitos, eles próprios dilacerados.

Ao ressaltar o termo dilaceramento, creio ter buscado abarcar o trabalho irreversível de decomposição da figura humana, nas artes do século XX. Decomposição que, embora visasse uma reconstrução, guardaria em camadas estratificadas, os processos dilaceradores da idealidade que a alicerçava, assim como alicerçava a própria representação. Inverte-se, pois, a dupla constituição da representação. Contemplando, primordialmente, a apresentação, as artes, no entanto, liberam rastros, vestígios, sintomas da representação; representação que se atualiza pelo dilaceramento formal e pela transitoriedade de seu evento. Esta é a minha hipótese e, como qualquer hipótese, é passível de ser questionada, problematizada e confrontada a outras leituras.

Abstract

This essay approaches the relations between representation and mimesis, investigating comparatively some writings of Georges Bataille and paintings of Francis Bacon. Both developed radical 
oeuvres according to the conceptual axis of deconstruction of the ideal anthropomorphic resemblance. Reading their works by the notion of Freudian figurativeness, it rethinks the reversion of representation in presentation and, mainly, their coalescence.

Key words: Representation. Mimesis. Figurativeness. Georges Bataille. Francis Bacon.

Referências

AUERBACH, Erich. Figura. São Paulo: Ática, 1997.

BATAILLE, Georges. O erotismo. São Paulo: Arx, 2004. [1957]

BATAILLE, Georges. História do olho. São Paulo: Cosac \& Naify, 2003. [1928]

COSTA LIMA, Luiz. Mímesis: desafio ao pensamento. Rio de Janeiro: Civilização Brasileira, 2000.

DELEUZE, Gilles. La logique de la sensation. Paris: Édition de la Différence, 1996.

DIDI-HUBERMAN, Georges. Devant l'image. Paris: Minuit, 1990.

DIDI-HUBERMAN, Georges. Fra Angelico. Dissemblance et figuration. Paris: Flammarion, 1995a.

DIDI-HUBERMAN, Georges. La peinture incarnée. Paris: Minuit, 1985.

DIDI-HUBERMAN, Georges. La ressemblance informe ou le gai savoir visuel de Georges Bataille. Paris: Macula, 1995b.

Marin, Louis. De la représentation. Paris: Seuil/Gallimard, 1994.

Marin, Louis. Le portrait du roi. Paris: Minuit, 1981.

Marin, Louis. Détruire la peinture. Paris: Flammarion, 1997.

TOFANI, Wanda de Paula. Imagem e figura: a representação em Georges Bataille e Francis Bacon. 2005. Tese (Doutorado em Estudos Literários) - Faculdade de Letras, Universidade Federal de Minas Gerais, 2005. 